\title{
PENINGKATAN KREATIVITAS KERJA MELALUI PENGUATAN KEPRIBADIAN DAN IKLIM ORGANISASI PADA GURU HONORER DI SMA NEGERI
}

\author{
Mulyadi $^{a)}$, Griet Helena Laihad ${ }^{b *)}$, Hari Muharam ${ }^{b)}$ \\ ${ }^{a)}$ SMAN 1 Citeureup, Bogor, Indonesia \\ b) Universitas Pakuan, Bogor, Indonesia \\ *)e-mail korespondensi: grihela@unpak.ac.id
}

riwayat artikel : diterima: 18 Juni 2020; direvisi: 21 Juni 2020; disetujui: 06 Juli 2020

\begin{abstract}
Abstrak. Kreativitas guru merupakan salah satu aspek penting yang menentukan keberhasilan pencapaian tujuan pendidikan, yaitu untuk mencerdaskan kehidupan bangsa. Penelitian ini dimaksudkan untuk menemukan upaya-upaya meningkatkan kreativitas guru melalui penguatan kepribadian dan iklim organisasi pada guru honorer SMA Negeri se Rayon Cibinong Kabupaten Bogor. Penelitian ini menggunakan metode penelitian korelasional, dimana pada tahap pertama penelitian dilakukan dengan menggunakan metode kuantitatif dan data dikumpulkan melalui penyebaran angket, lalu dianalisis dengan menggunakan regresi serta didukung oleh deskripsi statistik. Populasi penelitian ini adalah guru honorer serayon Cibinong sejumlah 174. Sampel penelitian sebanyak 122 responden ditentukan dengan rumus Taro Yamane dipilih menggunakan metode proporsional random sampling. Hasil penelitian kuantitatif menemukan bahwa kepribadian yang menekankan pada kestabilan emosi (emotional stability), keterbukaan (extroversion), mudah bersepakat (agreeableness), dapat diandalkan (conscientiousness) dan keterbukaan terhadap pengalaman (openness to experience) dapat berkontribusi untuk meningkatan kreativitas. Sementara iklim organisasi yang menekankan pada bertanggung jawab seorang anggota, struktur organisasi, penghargaan, standar kinerja dan lingkungan kerja dapat berkontribusi untuk meningkatkan kreativitas. Berdasarkan temuan dalam penelitian ini semakin kuat kepribadian dan iklim organisasi, maka diprediksi semakin tinggi kreativitas..
\end{abstract}

Kata Kunci: kepribadian; iklim organisasi; kreativitas

\section{IMPROVING STATE SENIOR HIGH SCHOOL HONORARY TEACHERS CREATIVITY THROUGH PERSONALITY STRENGTHENNING AND ORGANIZATIONAL CLIMATE}

\begin{abstract}
The creativity of teachers is one important aspect that determines the success of achieving goal of education that is for the building up the intellectual life of the nation. The study is intended to find out the efforts needed to improve the creativity of teachers through personality and climate of the organization of honorary teachers of SMA Negeri at Cibinong, Bogor District. This research is utilizing correlation methods of research, where the first phase of the research was carried out by using a method of quantitative and the data collected through the deployment of questionnaires, and then analyzed by using regression and supported by the description of the statistics. Population of the research were 174 honorary teachers of SMA negeri at Cibinong district. The sample study as many as 122 respondents were determined by the Taro Yamane formula that using the method of proportional random sampling. The results of the quantitative study revealed that personality which emphasizes the stability of emotions (emotional stability), openness (extroversion), easily agreed (agreeableness), can be relied upon (conscientiousness) and openness to experience may contribute to improve creativity. While organizational climate that emphasizes the responsibility of a member, the structure of the organization, award, standards of performance and working environment can contribute to improve creativity. Based on the findings, it is concluded that the stronger of personality and organizational climate, the higher creativity will be.
\end{abstract}

Keywords: personality; organizational climate; creativity

\section{PENDAHULUAN}

Pendidikan merupakan bagian penting dari pembangunan nasional yang ikut menentukan pertumbuhan ekonomi suatu negara. Pendidikan juga merupakan investasi dalam pembangunan sumber daya manusia, karena sumber daya manusia yang meningkat akan memperlancar terhadap perkembangan segala bidang. Isi dari Undang-undang No.20 tahun 2003 tentang Sistem Pendidikan Nasional pada pasal 3 menyebutkan tentang fungsi dan tujuan pendidikan nasional yaitu, pendidikan nasional berfungsi mengembangkan kemampuan dan membentuk watak serta peradaban bangsa yang bermartabat dalam rangka mencerdaskan kehidupan bangsa, bertujuan untuk berkembangnya potensi peserta didik agar menjadi manusia yang beriman dan bertaqwa kepada Tuhan Yang Maha Esa, dengan indikator berakhlak mulia, sehat, berilmu, cakap, kreatif, mandiri dan menjadi warga negara yang demokratis serta bertanggung jawab. Guru, menurut Undang-Undang Guru dan Dosen No. 14 tahun 2005, adalah pendidik profesional dengan tugas utama mendidik, mengajar, membimbing, mengarahkan, melatih, menilai, dan mengevaluasi peserta didik pada pendidikan anak usia dini jalur pendidikan formal, pendidikan dasar, 
dan pendidikan menengah. Selain itu, guru pada aras pendidikan sekolah negeri, dapat dikategorikan menjadi beberapa macam, yaitu guru tetap dan guru honorer.

Proses pembelajaran secara normatif harus sesuai dengan tujuan-tujuan pendidikan nasional, yaitu manusia Indonesia yang berkualitas dalam pandangan undang-undang bersifat multidimensi, pada rumusan tujuan pendidikan nasional tersebut menekankan bahwa profil manusia Indonesia berkualitas memiliki 10 (sepuluh) dimensi yaitu beriman, bertaqwa, berakhlak mulia, sehat, berilmu, cakap, kreatif, mandiri, demokratis dan bertanggung jawab untuk dapat mencapai tujuan tersebut dibutukan guru yang mempunyai kreatifitas. Gibson et.,al (2016:119-120) mendefinisikan kreativitas adalah perwujudan gagasan atau ide-ide yang unggul dalam bentuk peluang atau produk. Faktor-faktor yang mempengaruhi adalah: a. keyakinan diri dalam menemukan pemecahan masalah, b. keberanian bertindak, c. kecerdikan mencari peluang atau cara yang baru, d. keterbukaan terhadap ide-ide orang lain. Kreativitas dapat diasumsikan sebagai suatu proses psikis yang dapat melahirkan gagasan-gagasan atau konsep-konsep baru. Menurut Luthans (2011:267-268) Creativity is that it involves combining responses or ideas of individuals or groups in novel ways, kreativitas adalah suatu usaha melibatkan atau menggabungkan ide/gagasan dari individu atau kelompok dengan cara baru. Adapun indikator-indikatornya adalah: a. berpikir menggabungkan tanggapan kreatif, b. mengatur pola-pola baru, c. mengacu pada pengamatan, pengalaman dan pengetahuan. Colquitt et al., (2015: 306-307), kreativitas adalah penggunaan ide-ide baru dalam bekerja, memecahkan masalah dan melakukan tindakan-tindakan inovatif. Adapun yang mempengaruhi kreativitas adalah: a. senang mempelajari hal-hal baru, b. berupaya menemukan peluang atau cara-cara baru yang lebih baik dalam bekerja, c. keyakinan dalam bekerja, d. keterbukaan menerima ide-ide baru yang lebih baik. Selanjutnya Slamento (2010: 145) mengemukakan kreativitas adalah perwujudan sesuatu yang baik berupa ide, perbuatan maupun hasil karya yang berbeda dengan yang sudah ada serta memiliki berbagai cara dalam menghadapi masalah. Salah satu faktor yang mendukung, merupakan salah satu indikasi dan sumber kinerja guru dalam bekerja, berdampak pada perilaku kerja guru dalam mendidik siswa di sekolah, jika guru puas dengan pekerjaannya maka mereka akan bekerja dengan penuh semangat dan bertanggung jawab (Suchyadi et al., 2019). Berdasarkan kajian teori diatas dapat disintesiskan kreativitas adalah perilaku seorang individu dalam penggunaan ide-ide dengan merubah yang sudah ada atau membuat yang baru yang diwujudkan sebagai inovasi untuk menghasilkan produk. Indikator-indikatornya: a. berfikir kreatif, b. menciptakan ide baru, c. keingintahuan yang besar, d. inisiatif, e. alternatif memecahkan masalah.

Steven L McShane (2013: 39-40) menyatakan bahwa Kepribadian adalah pola yang relative abadi berupa pikiran, emosi, dan perilaku yang menjadi ciri seseorang, bersama dengan proses psikologis. Colquitt, LePine, and Wesson (2015: 200-201) mengungkapkan kepribadian adalah seperti apa seseorang (what people are like). Kepribadian sejatinya adalah kumpulan berbagai sifat. Kata sifat seperti bertanggung jawab (responsible), santai (easy going), sopan (polite), adalah contoh sifat yang dapat digunakan untuk meringkas kepribadian seseorang. Kreitner \& Kinicki (2008: 17) menyatakan kepribadian adalah kombinasi stabil karakteristik fisik dan mental yang memberikan identitas individu. Menurut Hawkins \& Motherbaugh (2013: 363-365) kepribadian adalah kecenderungan karateristik respon individu diseluruh situasi. Adapun faktor-faktor yang berhubungan dengan kepribadian antara lain: a. bentuk kepedulian untuk menjadi kelompok besar daripada sendirian ketika berbicara dengan orang lain, b. ketidakstabilan adalah moody, berpengarai, sensitif, c. agreeableness adalah simpatik, baik kepada orang lain, sopan dengan orang lain, d. keterbukaan untuk pengalaman adalah imajinatif, menghargai seni, menemukan solusi baru, e. membangun kesadaran adalah hati-hati, tepat dan efisien. Berdasarkan kajian teori diatas dapat disintesiskan kepribadian adalah perpaduan yang utuh dari karakteristik seseorang berupa pola perilaku, pikiran, emosi yang ditampilkan untuk berinteraksi dengan orang lain. Indikator-indikatornya adalah: a. emotional stability (kestabilan emosi), b. extroversion (keterbukaan), c. agreeableness (mudah bersepakat), d. conscientiousness (dapat diandalkan), e. openness to experience (keterbukaan terhadap pengalaman).

Menurut Kusdi (2011: 77-78) iklim organisasi adalah kesamaan persepsi para anggota suatu organisasi tentang sikap dan kebutuhan, definisi-definisi tentang tugas dan pekerjaan, serta hubungan manusia dengan lingkungan. Adapun faktor yang mempengaruhinya: a. kebebasan kerja, b. struktur organisasi, c. imbalan, d. tingkat perhatian, e. kehangatan hubungan, e. dukungan terhadap pekerja. Anthonia (2011:151-165) mendefinisikan persepsi karyawan dari lingkungan kerja dan bagaimana persepsi tersebut terkait dengan pekerjaan sikap pengaruh individu dan perilaku. Dengan indikator yaitu: a. kepemimpinan, b. partisipasi dalam pengambilan keputusan, c. tantangan pekerjaan, d. kebosanan dan frustasi, e. keadaan organisasi, f. kebijakan, g. karir. Kundu (2007: 99) menyatakan iklim organisasi adalah persepsi individu terhadap organisasi dan seperangkat alat yang mengatur perilaku individu. Adapun dimensi dari iklim organisasi yaitu: a. kebebasan, b. inisiatif, c. tanggung jawab individu, d. bimbingan, e. pengawasan, f. peraturan dan prosedur serta tujuan organisasi, g. promosi, $\mathrm{h}$. pujian dan bentuk reward, i. dukungan / kepercayaan yang diberikan oleh organisasi. Adanya hubungan positif antara budaya organisasi dengan sikap profesional (Suchyadi, 2017). Berdasarkan kajian teori di atas dapat disintesiskan bahwa iklim organisasi adalah persepsi seseorang terhadap lingkungan kerja dan mempengaruhi sikap individu dalam menentukan kualitas lingkungan kerja untuk mencapai tujuan organisasi sehingga membedakannya dengan organisasi lain. Indikatorindikatornya adalah: a. rasa tanggung jawab sebagai anggota organisasi, b. struktur organisasi, c. penghargaan (reward) bagi setiap anggota organisasi , d. standar kinerja, e. lingkungan kerja 


\section{METODE PENELITIAN}

Penelitian ini akan dilaksanakan di SMA Negeri se-rayon Cibinong Kabupaten Bogor Propinsi Jawa Barat, yang berjumlah 7 Sekolah Menengah Atas Negeri. Dalam melaksanakan penelitian ini akan mengambil rentang waktu 6 bulan lamanya, terhitung sejak bulan Oktober 2019 sampai dengan bulan Maret 2020, mulai dari pengajuan judul tesis hingga tahap akhir laporan hasil penelitian. Metode penelitian yang digunakan dalam penelitian ini adalah metode survei. Metode survei dengan pendekatan korelasional dilakukan terhadap sampel dari suatu populasi, kemudian menganalisa sampel, dan hasil analisa sampel diberlakukan untuk populasi. Populasi penelitian ini adalah seluruh Guru Honorer SMA Negeri Serayon Cibinong Kabupaten Bogor Provinsi Jawa Barat. Yang berjumlah 174 orang dari 7 sekolah. Jumlah sampel dari perhitungan rumus adalah sebanyak 121,25 yang dibulatkan menjadi 122 orang guru.

\section{HASIL DAN PEMBAHASAN}

\section{Hubungan Antara Kepribadian Dengan Kreativitas}

Hasil analisis korelasi sederhana antara kepribadian dengan kreativitas diperoleh nilai koefisien korelasi $r_{\mathrm{y} 1}$ sebesar 0,7259. Nilai ini memberikan pengertian bahwa keterkaitan antara kepribadian dengan kreativitas cukup dan positif, artinya makin baik kepribadian makin tinggi pula kreativitas tersebut. Demikian pula sebaliknya, makin kurang baik kepribadian, makin rendah pula kreativitasnya. Besarnya sumbangan atau kontribusi variabel kepribadian terhadap kreativitas dapat diketahui dengan jalan mengkuadratkan peroleh nilai koefisien korelasi sederhananya. Hasil pengkuadratan nilai koefisien korelasi sederhananya adalah sebesar 0,5270. Secara statistik nilai ini memberikan pengertian bahwa kurang lebih 52,70 persen variasi perubahan kreativitas ditentukan/dijelaskan oleh kepribadian dengan pola hubungan fungsionalnya seperti ditunjukkan oleh persamaan regresi tersebut di atas. Artinya, variasi pasangan skor kedua variabel tersebut akan berdistribusi dan mengikuti pola hubungan antara variabel kepribadian dengan kreativitas sesuai persamaan garis regresi $\mathrm{Y}=30,174+0,775 \mathrm{X}_{1} \mathrm{Hal}$ ini sejalan dengan penelitian yang dilakukan oleh Basith (2019:78), menghasilkan nilai sangat signifikan antara kepribadian $\left(\mathrm{X}_{1}\right)$ dengan kreativitas guru (Y). Kekuatan hubungan antara variable $\mathrm{X}_{\mathrm{I}}$ dan $\mathrm{Y}$ ditunjukkan oleh koefisien korelasi ry ${ }_{1}$ sebesar $0,321(\mathrm{p}<0.01)$

\section{Hubungan Antara Iklim Organisasi Dengan Kreativitas}

Hasil analisis korelasi sederhana antara iklim organisasi dengan kreativitas diperoleh nilai koefisien korelasi $r_{\mathrm{y} 2}$ sebesar 0,619. Nilai ini memberikan pengertian bahwa keterkaitan antara iklim organisasi dengan kreativitas cukup dan positif, artinya makin tinggi iklim organisasi akan makin tinggi pula kreativitas tersebut. Demikian pula sebaliknya, makin rendah iklim organisasi, makin rendah pula kreativitas tersebut. Besarnya sumbangan atau kontribusi variabel iklim organisasi terhadap kreativitas dapat diketahui dengan jalan mengkuadratkan nilai koefisien korelasi sederhananya. Hasil pengkuadratan nilai koefisien korelasi sederhananya adalah sebesar 0,3830. Secara statistik nilai ini memberikan pengertian bahwa kurang lebih 38,30 persen variansi perubahan kreativitas ditentukan/dijelaskan oleh iklim organisasinya dengan pola hubungan fungsionalnya seperti ditunjukkan oleh persamaan regresi tersebut di atas. Artinya jika SMA Negeri seRayon Cibinong diukur iklim organisasi dan kreativitasnya, maka variasi pasangan skor kedua variabel tersebut akan berdistribusi dan mengikuti pola hubungan antara variabel iklim organisasi dengan kreativitas melalui persamaan garis regresi $\mathrm{Y}=61,037+0,547 \mathrm{X}_{2}$.

\section{Hubungan Antara Kepribadian dan Iklim Organisasi Secara Bersama-sama Dengan Kreativitas.}

Hasil analisis korelasi ganda antara kepribadian dan iklim organisasi diperoleh nilai koefisien korelasi ganda sebesar $\mathrm{r}_{\mathrm{y} .12}$ sebesar 0,740. Nilai ini menunjukkan bahwa keterkaitan antara kepribadian dan iklim organisasi secara bersama-sama dengan kreativitas cukup dan positif. Colquit et al., (2011, h.306-307), kreativitas adalah penggunaan ide-ide baru dalam bekerja, memecahkan masalah dan melakukan tindakan-tindakan inovatif. Adapun yang mempengaruhi kreativitas adalah (1) senang mempelajari hal-hal baru, (2) berupaya menemukan peluang atau cara-cara baru yang lebih baik dalam bekerja, (3) keyakinan dalam bekerja, (4) keterbukaan menerima ide-ide baru yang lebih baik.

Besarnya sumbangan atau kontribusi variabel kepribadian guru dan iklim organisasi secara bersama-sama dapat diketahui melalui nilai koefisien determinasi sebesar 0,5483. Hasil analisis tersebut menunjukkan bahwa lebih kurang 54,83 persen variasi perubahan kreativitas guru ditentukan / dijelaskan oleh kepribadian dan iklim organisasi secara bersama-sama dengan pola hubungan fungsionalnya seperti ditunjukkan oleh persamaan regresi tersebut di atas. Artinya jika seluruh guru honorer SMA Negeri se Rayon Cibinong diteliti tentang kepribadian dan iklim organisasi secara bersama-sama dengan melihat kreativitas gurunya, maka variasi pasangan skor ketiga variabel akan mengikuti pola persamaan regresi $Y=26,199+0,617 X_{1}+0,184 X_{2}$

\section{SIMPULAN}

Hasil penelitian kuantitatif menemukan bahwa kepribadian yang menekankan pada kestabilan emosi (emotional stability), keterbukaan (extroversion), mudah bersepakat (agreeableness), dapat diandalkan (conscientiousness) dan 
keterbukaan terhadap pengalaman (openness to experience) dapat berkontribusi untuk meningkatan kreativitas. Sementara iklim organisasi yang menekankan pada bertanggung jawab seorang anggota, struktur organisasi, penghargaan, standar kinerja dan lingkungan kerja dapat berkontribusi untuk meningkatkan kreativitas. Berdasarkan temuan dalam penelitian ini semakin kuat kepribadian dan iklim organisasi, maka diprediksi semakin tinggi kreativitas...

\section{REFERENSI}

Anthonia, Adenike. (2011). Organizational Climate As a Predictor of Employee Job Satisfaction: Evidence From Covenant University. Business Intelligence Journal, Vol.4 No.1, January 2011, pp. 151-165.

Colquitt, Jason A., Jeffery A. LePine, and Michael J. Wesson. 2015. Organizational Behavior: Improving Performance and Commitment. Fourth Edi. New York: McGraw-Hill Education.

Gibson, James L, John M. Ivanecevich, James H. Donelly Jr, Robert Kanopaske. 2016. Organizations, Behavior,Structur,Processes,Edisi 14.New York:Mc Graw- Hill. Pp. 119-120

Hawkins, Del I, Mothersbaugh, David L. 2013. Consumer behavior : building marketing strategy eleventh edition. Boston: Mc Graw- Hill. Pp. 363-365

Kundu, Kaushik, 2007. Development of the Conceptual Framework of Organizational Climate Vidyasagar university Journal Of Commerce, Volume 12 ; 99-108.

Kusdi. 2011. Budaya Organisasi: teori, penelitian, dan praktik. Jakarta: Salemba Empat. Pp. 77-78

Kreitner, Robert and Angelo Kinicki.2008. Organization Behavior. New York:Mc Graw-Hill. Pp. 17.

Luthans, Fred.2011.Perilaku Organisasi, (AlihBahasa V.A Yuwono, dkk),Edisi.Bahasa Indonesia, Jakarta, PT Indek.

McShane, Steven L, Maryam.2013 Organizational Behavior: emerging knowledge and practice for the real world. New York: Mc Graw- Hill. Pp. 39-40

Slamento. 2010. Belajar dan Faktor-Faktor Mempengaruhinya. Jakarta: Rineka Cipta. Pp. 145.

Suchyadi, Y. (2017). Relationship between Work Motivation and Organizational Culture in Enhancing Professional Attitudes of Pakuan University Lecturers. JHSS (Journal Of Humanities And Social Studies), 1(1), 41-45.

Suchyadi, Y., Karmila, N., Nurlela, N., Mirawati, M., Purnamasari, R., Sri Indriani, R., ... Syahiril Anwar, W. (2019). Increasing Personality Competence Of Primary School Teachers, Through Education Supervision Activities In Bogor City. Journal Of Community Engagement (JCE), 01(01). 